\title{
Research on Technological Innovation Network of Colleges under Regional Economic Development
}

\author{
Aiwen Wang \\ School of Economics and Management, Guangzhou City construction College, Guangzhou 510925, \\ China
}

Keywords: Minority areas; Technological innovation network; Synergetic development; Countermeasure research

\begin{abstract}
The talents are the important guarantee for economic development, but the educational development level in minority areas can hardly meet the economic development demand in minority areas; the regional economy is closed related to the technological innovation network of colleges. This paper takes minority areas in west China as an example to carry out research, and combines with development status of technological innovation network of colleges in minority areas to analyze the factors which influence the development of technological innovation network of colleges in minority areas, and propose the suggestions about promoting the development of technological innovation network of colleges in minority areas for the purpose of promoting the development of technological innovation network of colleges in minority areas.
\end{abstract}

\section{Introduction}

In recent years, with the implementation of China western development, there is a significant economic development in minority areas. In particular, with the launching and implementation of "the Silk Road economic belt" strategy, the economic development in minority areas has clearer objective and stronger power. While improving people's livelihood and people's living standard, the powerful economic development also provides strong materials basis for development of technological innovation network of colleges. As an important content of social and economic development in minority areas, the technological innovation network of colleges is an essential source of power for rapid development of minority areas, and the incline of economy toward education is an inevitable result of social development.

Necessity of technological innovation network of colleges and economic synergetic development in minority areas

The economic development in minority areas provides a material basis for the technological innovation network of colleges.

The data shows: since 2012, with the incline of national finance toward minority areas, large quantity of educational and cultural infrastructure in minority areas recover to be reconstructed, the source of students increases, and the rapid rebound growth appears in the technological innovation network of colleges in minority area. In order to keep the good momentum of great-leap-forward development, the senior talents who keep a foothold in local area become the urgent need for development of minority areas. The educational form, technological innovation network of colleges, is directly related to the social and economic development, and the technological innovation network of colleges enhances the relation between economy and education, promotes the improvement of labor productivity, promotes the expansion of social productive force, and creates advantages for regional economic development.

The technological innovation network of colleges provides talent guarantee for optimization of industrial structure in minority areas

Based on overall structure of Chinese education system, the technological innovation network of colleges is a core part of modern national educational system related to talent cultivation. In order to 
realize a comprehensive, balanced, and healthy development of economic society, it is required to make overall planning and all-round consideration and greatly develop featured technological innovation network of colleges. Compared to other nationalities, the economic and cultural development in Chinese minority areas is backward. Under the background of backward economy and culture, the technological innovation network in minority areas not only undertakes the heavy responsibility of promoting the development of current economic society, but also shoulders the important mission of promoting national unity and common prosperity, narrowing the gap of western and eastern development, constructing harmonious socialist society, and constructing a new socialist countryside. In other words, the fundamental purpose is talent cultivation. As for the minority areas with backward economic level, their featured production and lifestyle are the lifeblood for educational growth and development, thus we need large quantity of local knowledge talents with regional spirit to drive the development. Therefore, it is required to greatly develop talent cultivation-oriented technological innovation network of colleges.

The synergetic development of technological innovation network of colleges and economy can ensure to realize stability in minority areas.

Located in frontier region, the minority areas have extremely important strategic position. Without the economic and social development in minority areas, there will be no national stability and development. In order to realize stability, the minority areas shall have a comprehensive, and effective political, economic, and cultural environment. In particular, in the internet era, the college students' political sense of identity is weakening in minority areas, their political centrifugal force is prominent, and the ideology and practical activities which deviate from moral rules required in the society are formed, which become the destabilizing factor seriously influencing the stability and social harmony in minority areas. The reason is that few minority college students are confined in era change of social structure and interest appealing, and the certain change happens in their mental mode and behavioral pattern. As the traditional propagation carrier and mainstream ideology value of collectivism culture in minority areas, the colleges shall meet the challenges and solve the problems. Therefore, the technological innovation network of colleges and economic development are always consistent with mature value orientation formed in minority areas and become "one body and two wings" in social stability, and the cooperative orientation of technological innovation network of colleges and economic development is reflected, which is convenient for solving ethnic problems and realizing the stability in minority areas.

\section{Problems existing in the development of technological innovation network of colleges in minority areas from economic perspective}

\section{The investment in educational resource for colleges in minority areas is insufficient.}

From objective perspective, the educational expenditure for technological innovation network of colleges in minority areas mainly comes from national fiscal educational expenditure, social and citizen's individual school funding, and social donation, etc. According to the proportion of external investment in technological innovation network of colleges at current stage, the national finance and local finance will make investment of $0.04 \sim 0.07 \%$ of GDP in recent 10 years into the field of technological innovation network of colleges in minority areas; in rent 10 years, the national finance and local finance will use $1.18 \% \sim 1.23 \%$ of GDP as fiscal educational expenditure for technological innovation network of colleges in minority areas. In terms of actual effect, compared to actual demand on technological innovation network of colleges, the investment proportion is very low. It can be said that the expenditure for the technological innovation network of colleges in minority areas accounts for the lowest proportion in local education expenditure; compared to developed areas in middle and east China, this imbalanced proportion intensifies the imbalanced educational development in the minority areas. Meanwhile, there is a little incline of public finance toward vulnerable groups, especially the compensation for educational expenditure, and subsidiary for students in minority areas, thus a series of educational injustices are caused. 


\section{The colleges in minority areas face the crisis of source of students.}

Firstly, due to historical and geographical reason, the minority areas have a weak economic base, low cultural level, and slow social development compared to other areas. Especially in remote region, people have very weak awareness of application and spreading of scientific and technological knowledge. Secondly, since the ancient times, a kind of relatively peaceful and stable relation of subordination has been formed between people of minority and nature, and this lifestyle of "make living with the local advantages" makes them be content with the status and have little expectation; they think that the study is useless for their current life and have weak demand of being educated. Thirdly, people have narrow information channel and don't know the education and teaching content of technological innovation network of colleges; they always confuse higher education institutions with technician training schools, and think that the schools just teach one skill. They have deep prejudice over technological innovation network of colleges and get no clear knowledge of the importance of developing technological innovation network of colleges. Based on above reasons, many colleges have no source of students or have low quality of source of students, and the higher education institutions in minority areas face serious survival crisis, thus causing difficult recruitment of colleges and difficult completion of enrollment plan.

The major setup of colleges in minority areas is not matching with talent demand.

On one hand, the economic development requires large quantity of practical talents. The minority areas are typical inhabitation areas of minorities, thus the post demand is different from that in other areas. Driven by China western development, the minority areas realize rapid development in economy, science and technology. Therefore, the higher requirement is proposed for laborers' comprehensive quality; due to influence of change and adjustment of industrial structure and employment structure, the laborers' cross-industry flow is accelerated. Meanwhile, large quantity of emerging industries have realized significant development, such as national ecological tourism, national handicraft, national ecological agriculture, national medicine, and national food. With the development of emerging industries, there are continuously expanded demand for senior technical talents who master national featured technology, thus the higher and higher requirement is proposed for major setup of technological innovation network of colleges in minority areas. On the other hand, the major setup of colleges is not timely updated. In order to reduce the cost and making a living, the major setup of colleges has a slow updating speed and can't meet the special demand of current economic development in minority areas. For example, the development of export of cultural products in minority areas both requires that the students can be familiar with local featured products at the stage of technological innovation network, and requires that the students have the ability in export management of foreign trade. In terms of curriculum provision, the technological innovation network of colleges in minority areas only pays attention to theoretical teaching of foreign trade knowledge, but gives few introduction to local featured cultural products and folklore characteristics. In terms of practice, the students can only get a chance to take internship in the workshop subordinate to their schools before graduation; the main internship form is viewing and emulating, and the students basically have no time chance to contact the practical operation. This results in the situation that the students lose the innate advantage of enhancing their featured culture, blindly follow the group, have single skill, and get a superficial understanding of knowledge and skills; the serious splitting between students' quality and current talent demand appears.

\section{Countermeasures for optimized development of technological innovation network of colleges and economy in minority areas}

To enhance the fusion and symbiosis of technological innovation network of colleges and regional economic culture

The education is a quasi-public product with social benefit and market benefit. Therefore, from perspective of public economics, the education cost shall be invested by government and borne by the market. Under the condition of market economy, the social fund breeds unlimited potential. It is 
required to carry out positive guidance via policies, fully exert the leverage regulation function of economy, and absorb large quantity of support from social fund in the development process of technological innovation network of colleges in minority areas. Since the birth of human culture, the education also emerges at the right moment; as a part of culture, the education makes human civilization continuously inherited; it can be said that there will be no vitality in case of no educational culture, and the education without culture lacks of connotation. Since the ancient times, the rich ethnic culture has been formed in the minority areas; those cultures are multi-level and multi-type, and they are unique and irreplaceable; through combination with local education, those cultures can realize the purpose that the education inherits the culture, and it is required to keep their mutual respect and effective fusion.

To expand the overall optimization of economic and operation mechanism of technological innovation network of colleges

The enterprises are the important force of the society, and also the main employment place for technological innovation network; through adding public service by enterprises, it is able to exert positive function in many aspects of technological innovation network. The economic development and skill education development in minority areas need to be pushed by enterprises. On one hand, the enterprises need to pay certain public service expenditure or join school-running upon employment to solve the problem that the demand of technological innovation network is insufficient. On the other hand, through enterprises' improving water, electricity, gas, traffic, and surrounding environment of technological innovation network, the technological innovation network can obtain preference, mitigate burden, improve the attractive force, optimize resource configuration and combination, realize the rising and better development, and avoid to fall into the vicious circle of "dragging income level $\rightarrow$ insufficient investment in human resource $\rightarrow$ poor make-living ability $\rightarrow$ lower income level".

To perfect the teaching reform of technological innovation network of colleges which adapts to economic development

Firstly, there is no time to delay the textbook compilation and reform of curriculum provision. There are three aspects involved. The first aspect is that we shall establish the local curriculum which adapts to local economy, culture, and society, and add the local textbooks suitable for cultural development of community to make students master specific make-living skills, obtain the awareness which adapts to social life, and adapt to social development demand. The second aspect is that we shall pay attention to improving cultural knowledge in curriculum provision, and teaching advanced management knowledge, science and technology to students so as to let students master the traditional skills with strong practicability. The third aspect is that we shall focus on pillar industry and featured economic industry, and combine with a series of scarce talent cultivation engineering implemented by the state to explore the new development mode of technological innovation network which takes professional development as link, takes school-enterprise cooperation as key point, takes improving laborers' quality as purpose, and realizes mutual complement, mutual benefit, low investment, and high output. Secondly, the teaching content shall start from actual condition in minority areas. It is required to add some knowledge related to cultivation, plantation, management, and maintenance, involve common knowledge of relevant laws and regulations, focus on increasing farmers' income to expand the teaching in cultivating and planting varieties and technological innovation, and improve the factor of merit and commodity rate of industrial crops. Thirdly, it is required to pay attention to the practicability of teaching content. As for technological innovation network of colleges in minority areas, there exists the phenomenon that more attention is paid to books but less attention is paid to practice; the students have poor operation ability and it is hard for them to adapt to the demand of social development and economic growth. We shall enhance the adjustment on teaching content, enhance skill training, enhance the close relation between theory and practice, cultivate students' operational ability and practical skills, and highlight the "higher" feature of technological innovation network. Fourthly, we shall adjust technological innovation network toward labor market. The fluctuation and competition become obvious features of labor market; in terms of curriculum provision, the development of technological innovation network of colleges in minority areas shall be established in the actual condition of labor market, make timely adjustment 
and enhancing on the direction, and take the realistic demand of employment market as basis to quickly and effectively give a response and fully reflect the flexibility of technological innovation network of colleges.

\section{Conclusion}

In conclusion, the technological innovation network of colleges in minority areas can realize continuous development through continuously absorbing local national culture, and the national culture can also continuously perfect itself with the development of technological innovation network of colleges. In order to realize the symbiosis development of culture and technological innovation network in minority areas, it is required to keep their mutual respect and effective fusion.

\section{Acknowledgments}

This paper is Guangdong provincial educational science “ $12^{\text {th }}$ Five-year" planning research project (2013JK323), special fund for Guangdong provincial higher institutions subject and specialty construction (subject research) project (2013WYXM0153), and Guangdong provincial higher vocational and technical educational seminar research topic (GDGZ14Y039).

\section{References}

[1] Lu Jieying: Evolution and Enlightenments of Value of German Technological Innovation Network of Colleges, Higher Technical Education, 2013 (13), p76.

[2] Zhao Xingmin: Challenges and Countermeasures in Regional Adapting Process of Technological Innovation Network of Colleges in Minority Areas, Guizhou Ethnic Studies, 2012 (3), p45.

[3] Lei Bin: Multi-culture and School Development in Minority Areas, Volume 4 of Chinese-British Minority Areas Basic Education Projects Yunnan Achievements, Yunnan University Press, version 1 of October 2014, p22, p29.

[4] An Zhongxuan: Comparative Study on Industrial Structure and Economic Growth in Minority Areas before and after Western Development - based on shift-share analysis method, Regional Economic Studies, 2012 (2), p11. 